\title{
Requirements for In-Situ Authoring of Location Based Experiences
}

\author{
Mark J. Weal \\ University of Southampton, UK \\ mjw@ecs.soton.ac.uk \\ Danius T. Michaelides \\ University of Southampton, UK \\ dtm@ecs.soton.ac.uk
}

\author{
Eva Hornecker \\ University of Canterbury, NZ \\ eva@ehornecker.de \\ David E. Millard \\ University of Southampton, UK \\ dem@ecs.soton.ac.uk
}

\author{
Don G. Cruickshank \\ University of Southampton, UK \\ dgc@ecs.soton.ac.uk \\ John Halloran \\ Coventry University, UK \\ John.Halloran@coventry.ac.uk
}

\author{
David C. De Roure \\ University of Southampton, UK \\ dder@ecs.soton.ac.uk
}

\author{
Geraldine Fitzpatrick \\ University of Sussex, UK \\ geraldin@sussex.ac.uk
}

\begin{abstract}
In this paper we describe an investigation into the requirements for and the use of in-situ authoring in the creation of location based pervasive and UbiComp experiences. We will focus on the co-design process with users that resulted in a novel visitor experience to a historic country estate. This has informed the design of new, in-situ, authoring tools supplemented with tools for retrospective revisiting and reorganization of content. An initial trial of these new tools will be discussed and conclusions drawn as to the appropriateness of such tools. Further enhancements as part of future trials will also be described.
\end{abstract}

\section{Categories and Subject Descriptors}

\section{H.5.1 [Multimedia Information Systems]:}

\section{General Terms}

Design, Human Factors

\section{Keywords}

authoring tools, in-situ, location based experiences

\section{INTRODUCTION}

Developing engaging user experiences for public environments has become a prolific research topic, particularly in the context of deploying novel technologies as provided by ubiquitous, pervasive and mobile computing [3, 13]. Particular interest has been given to the design of novel visitor

Permission to make digital or hard copies of all or part of this work for personal or classroom use is granted without fee provided that copies are not made or distributed for profit or commercial advantage and that copies bear this notice and the full citation on the first page. To copy otherwise, to republish, to post on servers or to redistribute to lists, requires prior specific permission and/or a fee.

MobileHCI'06, September 12-15, 2006, Helsinki, Finland.

Copyright 2006 ACM 1-59593-390-5/06/0009 ...\$5.00. experiences to museums and historic sites. Yet to museum experts it is a well known problem that digital tour guides quickly become outdated. Reasons for this include that their content is usually defined and authored in a lengthy process involving not just the domain experts, but also outside experts for design and technology as well as professional speakers or actors. Changes and additions thus require expertise in the use of tools, investment into design and creation of content and costly external resources. Putting authoring into the hands of curators and other stakeholders who wish to create their own, specialized experiences and activities would alleviate this problem.

As part of the Equator IRC (Interdisciplinary Research Collaboration) we have been working with Chawton House Library, to create novel pervasive experiences for its visitors. Chawton House Library operates it as a study centre of early English women's writing. The wide variety of visitors that come to the house such as academics studying at the Centre, coach parties from various organisations, such as the Jane Austen Society of America, groups of schoolchildren, etc. make it an ideal location for developing an infrastructure to support a wide variety of pervasive experiences.

We have worked with the curators on a visitor system in the tradition of locative information systems $[3,1]$. In addition, we have also been working with teachers from Whiteley Primary School, to create an augmented field trip for a group of Year 5 students (aged 10-11) using the same underlying infrastructure and information model. Whereas other locative, context-based learning experiences for children have focused on aspects of the curriculum such as scientific discovery [13], learning about nature [4], learning about history, etc., here, the main emphasis was on using the landscape as a writing aide within the literacy curriculum.

The children explored the grounds and constructed stories around their discoveries (see [6]). In order to achieve this, the teachers had to create a set of instructions and activities for the children which became available at various locations around the grounds. These activities incorporated a selection of audio clips which had been created by the curators as part of the content for a visitor system. The first phase of the project focused on the development of the underlying in- 
frastructure to support such activities [16] and the co-design of the experiences with both the curators and teachers [5, 15]. In this paper we look at this process of authoring and discuss how this has informed the design of in-situ authoring tools in combination with tools for revisiting, editing and reorganizing authored content. The emphasis here is in designing and building tools for experience builders to sit on top of an existing persistent pervasive infrastructure.

We will discuss related work in the field of Ubiquitous and in-situ authoring before outlining the project (Section 3) and giving an overview of Chawton House and its operation. Section 4 gives details of the workshops that were run with curators and teachers to co-design experiences followed by analysis of what lessons were drawn from this process (Section 5). Section 6 discusses the requirements for and the design of in-situ authoring tools to facilitate the creation of such experiences. Section 6.1 discusses an early trial with these tools followed by Conclusions in Section 7 .

\section{RELATED WORK}

Work on authoring and design for ubiquitous systems tends to have concentrated on the system designer, with the assumption that they would also be deploying and maintaining the system. Component approaches have been taken to make this easier, where components or widgets provide an interface for obtaining contextual information about their environment [14] and an API allows them to be controlled. Such approaches still require components to be orchestrated programmatically. Other work, such as the iStuff framework, provide an interface for connecting and orchestrating devices in a ubiquitous system [2].

The Urban Tapestries project looked at the idea of public authoring [8], where members of the public could create locations in an ubiquitous system by uploading GPS coordinates, and then attach media items such as notes or photos, either in-situ using a PDA or at a later point on a web site. Annotations are made in threads, and browsers can select which threads they wish to see. In this way Urban Tapestries was handing some of the design to the users, and allowing non-technical people to create a ubiquitous experience. M-studio is another system that allows users to create an experience by authoring content [12]. M-studio delivers video content to PDAs according to their location. A graphical authoring tool allows authors to place video content at locations, but also supports storyboarding and simulated located playback, so authors can check the effect of movement on their narratives.

Other work has looked beyond authoring and delivery of information to interaction, allowing users to specify devices and rules to describe their interactions. Kolo is a control system that connects sensors and devices in ubiquitous environments, and processes simple scripts to control them [10]. Kolo was designed to allow artists to incorporate ubiquitous computer systems into their work. However, while the scripting language provides a simple API to the Kolo network it is still intended for artists with a high level of technical awareness. Topiary is a rapid prototyping system that uses a higher level of abstraction (people and places, rather than sensors and devices). Topiary allows authors to storyboard, situate and simulate information placed into a geographic environment on a map [9]. Topiary also supports automatic pathfinding and more advanced trigger conditions based on user and place (such as user1 and/or user2 are near, etc.). Evaluation results show that users find topiary's graphical approach easier than logic-based rules.

The eDiary [7] allowed architecture students, running on an IPAQ to record their path during a site visit, using an IPAQ which would map photos and notes to a map of the site. Later-on this could be edited on a PC and the path calibrated to the map. Nodes of the path, representing locations where notes had been taken, could be moved or expanded. The annotated map then was used in multi-media presentations on the site visit. While this system bears resemblance to ours in featuring a two-phase process of in-situ content capturing and subsequent reorganization and refinement, it is not aimed at the authoring of mobile and location-based user experiences.

In our own work we have noted that non-specialist designers find it difficult to work away from the context in which their design will be experienced. With this in mind we have taken a similar approach to Topiary, but concentrated on a two phase authoring process alike the eDiary, where the first phase is done in-situ, thus resulting in content that is more strongly contextualised.

\section{THE CHAWTON HOUSE PROJECT}

The overall aims of the Chawton House project were 1) to develop a persistent infrastructure that can support a wide range of experiences that draw on common resources such as defined locations and audio clips. 2) to learn about the needs of user authoring in this context in order to develop authoring tools.

A set of workshops were held with curators and teachers aimed at understanding current practices around giving tours and conducting school fieldtrips. In the course of these workshops, two types of experiences were authored. The first was a simple locative visitor audio tour created by the curators of Chawton House. Content creation involved the in-situ recording of audio content by the curators which was marked up with appropriate context metadata. This was a manual process with the audio recordings of the curators being chopped into discrete anecdotes and marked up by hand with information such as location. There would be an archive of 'content', i.e. various media including text and audio, about the grounds. This archive could be accessed and customized in different ways. The second experience was a literacy fieldtrip for schoolchildren created by teachers from Whiteley Primary School (see [6]). Content created by curators would be reused by teachers and integrated into a set of activities which had children explore the grounds, learn about its history, start to observe and describe the environment and use this as inspirational materials for creative writing. These experiences were created in co-design workshops with curators and teachers.

With both stakeholder groups we held three workshops each before the literacy fieldtrip was carried out. Following the fieldtrip, we interviewed two of the curators individually and conducted a group interview with the two teachers. We also held interviews with the children to evaluate the trial (see [6]). Throughout this sequence of workshops we collected insights on requirements for authoring tools.

\subsection{The School's Literacy Fieldtrip}

The literacy fieldtrip used the infrastructure to support an exploratory and creative activity for a group of children; steering them through the gathering of material for later use 
in the generation of a fictional story. The teachers devised a scenario where, at various locations around the grounds, the children would be given activities to carry out. These might be to write in their exercise books, to play-act a situation, record pieces of text or audio on the PDAs or just to stop and take in their surroundings.

The teachers used most of the locations previously identified by the curators but added some specific locations that were appropriate to the literacy exercise. In addition to creating the activities, the teachers also selected audio clips created by the curators that could be presented to the children to support their understanding of the landscape and house and to trigger their imagination. The persistent infrastructure was designed to support this form of re-use. As well as location information the teachers also specified durations for the activities and the order in which a set of activities should occur within locations.

On the day of the trials, the children were first given a traditional guided tour of the house to set the scene before being divided into pairs for the later activities. They had been given a brief tutorial on how to use the PDA device at their school. The literacy experience had two parts to it. In the first phase the children could explore the grounds freely, gathering information, impressions and inspiration at various locations as they carried out the sequences of activities (see Figure 1). The children were then gathered together to briefly share their findings with each other before moving on to the second phase, where they went back to two locations of their choice and received further instructions on more specific activities to help in the creation of their stories.
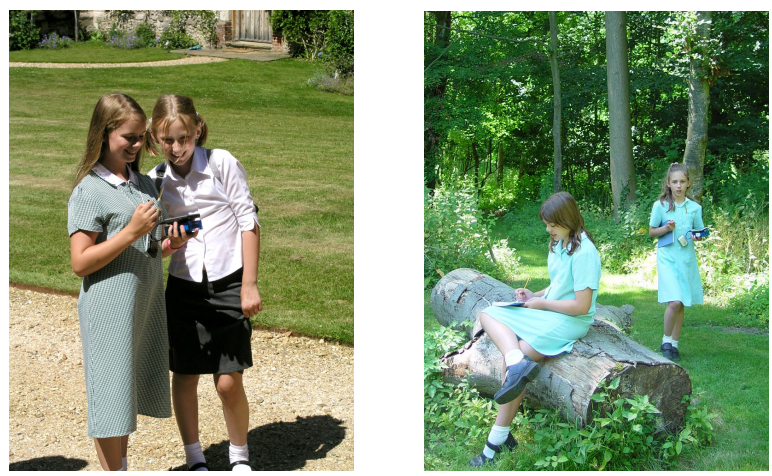

Figure 1: The children during the trial.

\section{AUTHORING WORKSHOPS}

Co-design workshops were planned and organized with our two groups of users. Workshops with curators were focused on understanding the setting, discussing concepts for deviceenabled tours and collecting content. Workshops with teachers focused on understanding the practice of organizing and conducting fieldtrips and designing structure and instructions for one.

\subsection{Overview of Workshops with Curators}

Before the fieldtrip, three workshops with curators took place, all at Chawton House itself. After the fieldtrip a 'feedback workshop' was conducted, using the prior experience of the fieldtrip as input for discussion of further plans.

The first curator workshop had three aims: to understand curators' current practices, to find out what kinds of things they tell visitors about the grounds, and to discuss possible types of tours for visitors. The discussion was grounded with a large map populated with models of buildings. Curators placed annotated post-its on the map representing stories they would tell in these places (Figure 2).
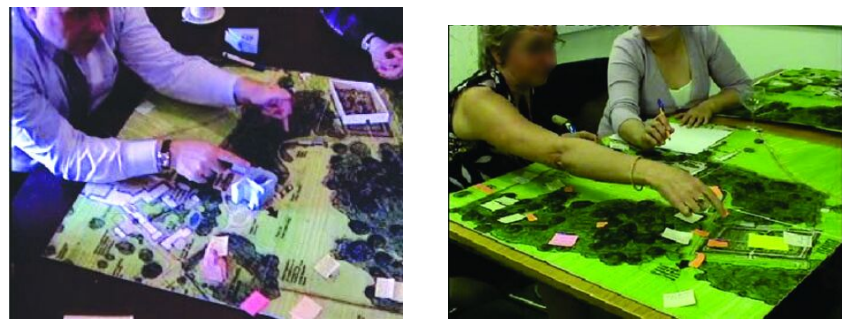

Figure 2: Using maps in co-design workshops.

The workshop initiated discussion about current practice, about issues that a guide system could help to address, and provided curators with a beginning understanding of our design vision. We learnt that curators have created a 'basic script' for tours that entails the information that every visitor should hear, but that they deviate from and improvise on this according to the specific interests of visitor groups. The script serves as a "point of reference" for them, and is occasionally revisited and reworked. Curators might also devise a specific script for a new kind of visitor group. Originally we had wanted to record some of the stories visitors are told, but we found that curators were not used to telling stories when not on location. Following a suggestion by one of the curators it was decided to use the next workshop to record actual tours in order to generate content.

During the second workshop with curators, Sue, Alan and Greg each took a pair of researchers on separate guided tours, which we videotaped (see Figure 3). In reviewing the tapes we realized that curators can only authentically tell stories when on the grounds - these situated recordings were much livelier and often more fluent than the stories we had previously recorded. We also learnt that tours are to some degree directed by a script but at the same time improvised in light of visitors reactions and - in particular triggered by being in location.

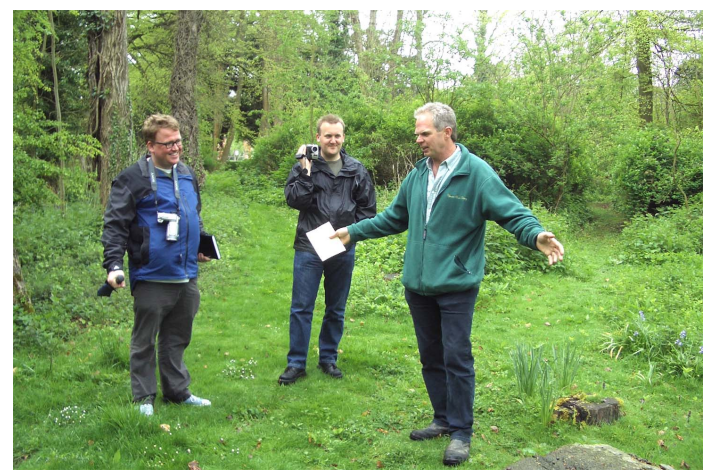

Figure 3: Recording a tour.

It was decided to use a selection of 'authentic' recordings from this second workshop (instead of re-recording them with professional actors), retaining curators' voices, humour, 
energy and authority. This approach would furthermore enable curators to extend the content database by recording additional stories, selecting sections and thereby building an oral archive of knowledge. At this stage the research team selected and cut the recordings into short snippets for reuse. These would be made available to the teachers as material to employ for the fieldtrip. There are problems with this style of audio recording however. Ambient noise, although lending atmosphere is not controlled and can be distracting. The quality of audio captured is also highly variable due to the quality of the audio equipment, distance from microphones etc. This is part of the trade off between easily authored material created by domain experts as opposed to that which requires high quality post-production both in terms of time and additional resources.

The third workshop started with a walk outside the house with a laptop, playing selected audio clips to give a first impression of how visitors might experience this. The curators were then presented with clips transcribed onto separate cards. The aim of this exercise was to explore how content could be put together in different ways to create different kinds of experience. The curators were not used to hearing themselves recorded or to think of stories arranged in new ways from separate parts (in giving a tour they aim to choreograph the entire tour). They realized how "each one stands alone" and could be juxtaposed in new compositions, detached from its original context of creation/recording. Curators were mainly concerned with the correctness of the stories and asked the research team to sort them into categories as they were not used to think of them in these terms.

The fourth (feedback) workshop gave curators the opportunity to reflect on the school fieldtrip that two of them had observed and to explore how we could proceed to devise novel visitor experiences. Curators were presented with a video overview of the fieldtrip and then walked around the grounds for fifteen minutes with the device, enacting the same kinds of activities that children had engaged in. This enabled the curators to see how the material created by them had been reused. The discussion emphasized how visitors could have an active role in the visit experience, not only by choosing their individual route, but also by doing recordings of their own (as the children had done) and how similar explorative and creative activities could be offered to other groups of visitors, e.g. creative writing clubs.

\subsection{Overview of Workshops with Teachers}

We conducted three workshops with teachers prior to the fieldtrip. The day following the fieldtrip, the children continued their creative writing activity at school. The teachers were interviewed for further feedback on the success of the event and their suggestions on how to support authoring of fieldtrips.

The first workshop with teachers took place in one of our research labs. Together we designed a rough structure for a fieldtrip, using the same map as with curators to help remember the features of the grounds (which teachers had visited earlier). The workshop gave us insight into how teachers design fieldtrips, their educational value, and how they are organized. The map focused discussion about the event's structure and general orchestration. It was decided to have three phases, starting with a tour of the house by a curator. Then the children would explore the grounds freely, and in a third phase focus on two locations and start to conceptualise stories.

For the second workshop we visited the teachers at Whitely Primary School. The map was used again to revisit the initial sketch of the fieldtrip. We also had a set of audio clips from curators that teachers might reuse. It was decided to select short clips that provided historical or social context for the children's stories, and to use these in conjunction with instructions and prompts from teachers and displayed by the devices. The teachers used the map to place notes where events could happen and instructions be given. The fieldtrip structure was refined, thinking about the length of phases and types of activities for each. However, when it came to deciding on concrete activities and instructions, the teachers hesitated, as these would need to relate to concrete features of the grounds. It was therefore decided to meet for a third workshop on location at Chawton House so that the teachers could design the experience 'in-situ'.

The third workshop with teachers, at Chawton House, was focused on finalizing the fieldtrips details. While walking the grounds with us, the teachers brainstormed ideas for specific activities and instructions suited to the locations, using background information and an overview of suitable audio clips (Figure 4). Back in the house, ideas were selected and refined and timings discussed for e.g. how long children should stay at a location and how instructions would be sequenced. This was commenced via email, sharing notes, finalizing the text for instructions and refining the orchestration, with the researchers manually transforming the descriptions by teachers (in a simplified description language) into machine readable format.
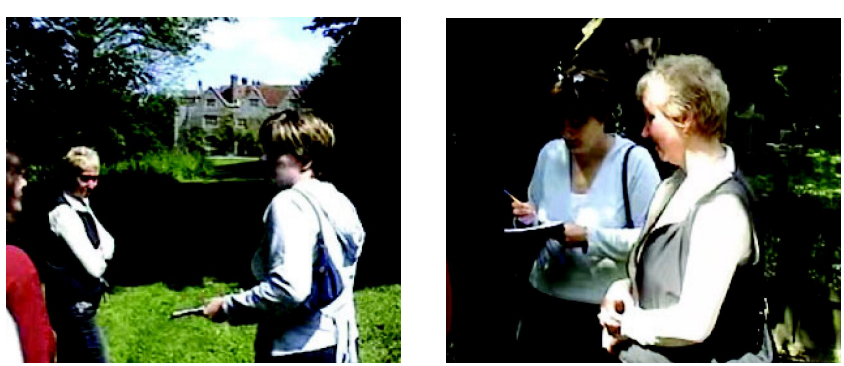

Figure 4: Teachers brainstorming in the grounds.

\section{INSIGHTS GAINED ON REQUIREMENTS FOR AUTHORING TOOLS}

From the experience with both groups of users we learned that the ability to author on location is essential to authoring for mobile experiences which are intrinsically connected with geographic features, topology or ambience. At the same time there needs to be facilities to revisit content, to refine it and to author more complex activities which require having an overview of content and to rearrange it in different ways.

The curators felt unable to tell stories naturally while not in-situ. Furthermore we found that being on location changed the quality of their story-telling, and enabled them to give more specific references e.g. to certain views that are only available from a specific point in the gardens. While walking the grounds, they are often triggered by incidents and sights to tell stories that they do not tell in other sit- 
uations. Thus in-situ authoring would fit with their established practices while extending them. This practice had been suggested in the first workshop by Alan as an alternative to recording stories around a map: "the best way to capture the basic info (...) is to actually follow round with a tour, and record that. (...) to add to it, the easiest way to do that is to film it, to record it, and somehow get that into the system. Because otherwise it would be a chore." Thus authoring should not be "a chore", but as simple and easy as possible, something to do on the side, incrementally.

While it seemed initially difficult for curators to think of stories in isolation, and to envision them being rearranged and categorized, over the course of the project they appropriated the concept of isolated audio clips and found it interesting to juxtapose clips from different curators, who "all have different approaches" (Sue). The possibility to change content fits with their practices. Sue comments "the more you use it and you find which areas people are using more than others, you could then adapt the content to reflect that", and spins off ideas on how to utilize the device that, "the information that we give out on such a system could be seasonal or trying to get people to imagine what an area of the garden would look like at a different time of year."

Given that the work of curators not only consists of the situated practice of story-telling, but also of developing " $a$ basic tour script" and to research stories, not every part of authoring needs to be done on location. E.g. revision of tour scripts is often done over the winter, when there are few visitors and written up in the house, where one is free from the weather conditions. We therefore believe that curators' authoring can be split quite naturally into mobile, situated recording of stories using a small handheld device carried around during outside work, and a more reflective activity on a traditional desktop computer, reviewing recorded content, putting together tours and writing longer text snippets that are displayed on the device.

A similar observation held for the teachers' authoring activity. The overall design of the fieldtrip's structure and high-level activities was well supported by the map. Yet, for thinking of concrete activities the teachers needed to be on location, picking up inspiration for their brainstorming and evaluating ideas immediately (whether they fit the place). While walking around the teachers talked a lot with each other, continuously shifting between ideas for specific activities and high-level organization of the fieldtrip and how activities would feed into each other. They made notes while walking around, that they reviewed when back in the house. Here they were taking final decisions, selecting ideas from their notes, rephrasing and revising instructions for activities and putting them in sequence. Walking around with a portable device, teachers could record or type in ideas which would get tagged with the location they were created at. At a later point they could reorganize and revise these notes at a desktop computer.

The teachers also stressed that authoring should not take much time. A clear message from Leila was that in preparing fieldtrips teachers expect to spend "half a day" visiting the place upfront and talking it through, plus "the odd half hour in school, just preparing for it." By giving access to the system and allowing final design on a web-based interface teachers would be enabled to do bits of work whenever they have spare time in their daily work duties. The requirements for authoring tools can be summarized as follows:
(1) They need to fit with existing practices and the effort for authoring content should be eased so as to be simple, quick, and doable in-between other daily activities when appropriate or when new ideas ask to be captured.

(2) In-situ authoring should be supported. This is particularly important if the mobile experience created is intrinsically connected with the environment, if authoring is easier for content creators when in-situ, and if this fits or builds on existing practices.

(3) The system should provide the option to revisit and refine content and to author more complex structures or sequences of content. This more reflective, time-intensive, and less ad-hoc activity does not need to be done in-situ and might even profit from detachment from the site. The content base should be open to ongoing changes.

\section{IN-SITU AUTHORING TOOLS}

Having constructed the underlying infrastructure to support the pervasive experiences we now wanted to place tools in the hands of the experience builders themselves that allow them to construct the experiences with a minimum of assistance from the researchers. It had become clear that in-situ authoring was a natural way for the curators and teachers to operate so we designed a PDA based tool to allow them to capture their audio clips, define locations and create activities whilst walking around the grounds themselves. In addition to the PDA based tool a desktop authoring tool is under development for authoring that does not require the content creators to be in the grounds for further steps such as categorising of audio clips and sequencing content items.

Throughout the project we relied on the metaphor of cards for items of content. Audio clips or instructions were represented as 'cards' which could be annotated with contextual meta-data and put into sequences. The card metaphor was continued through into the authoring tool. This allowed the experience authors to view the material they create in the same way as the eventual experience participants would.

The authoring process involved the creation of both content and metadata. The following list forms the core of the information that was required during the creation of the experiences: content (audio, text); location context; categorisation context (botany, historical, architectural etc.); timing information (for children's activities); prerequisite connections within content (to allow information to be developed over time, from basic information to more complex). Some of this can be easily captured in-situ (content, location) whereas other types of information gain less from this approach.

A simple interface gives the content creators the ability to define locations (both as a point location and as an area), create audio or textual information cards and define activities, either through simple text instructions or with instructions to record one's own text or audio. To create a new item, such as text instructions or an audio clip, one needed to create a location first and to name it if one had not done so prior. If authoring a new audio clip, one selected 'audio clip' from a list of pop-up options and on the new screen was offered a start and stop button for recording. After recording, one was presented a screen with the option to listen to the recorded clip, to rerecord it or to finish and name the clip. Text input in general was done with the integrated pop-up keyboard of the PDA and a stylus.

A trial was carried out with one of the curators to look 
at how usable this prototype was and to assess whether one mechanism for creating location felt more natural than the other.

\subsection{Results from the First Trial}

Sue, the assistant librarian that had been involved throughout the project took part in this trial. We first showed her how to work the device while still inside the house and then went outside, where Sue used it to create locations and to record clips. The objective was not to record final content, but to test the device, see how she could imagine using it, and to gather feedback for the ongoing system design. After 20 minutes we went inside and explained to Sue how the more reflective authoring phase would work, showing her an initial prototype holding the cards from the literacy fieldtrip. This led into a more focused interview with Sue about her suggestions and impressions. Based on transcriptions of recordings made we will now discuss our findings.

Sue quickly understood how the device worked after being walked through once and scaffolded on the first three instances, although as she claims, she is not "used to such high-tech." She was less nervous about being recorded than earlier when she had gone with us on a guided tour, but noticed that with the device she needs to think of what to say before clicking on record. Doing recordings requires curators to more consciously devise a story, and to explicitly start and end it, whereas in guided tours this is part of a continuous flow. Sue felt that this could be quickly learnt and might even be easier when walking around on her own. After the first few tries she started enjoying the activity, telling us "I'm getting the hang of it now!", and asking us to go on with her to the next location in the grounds.

Sue used the simple audio capture interface (figure 5) to record a number of anecdotes. We observed that she sometimes walked on while recording, similar to curators' behaviour during actual tours. Holding the device in her hands made Sue talk down to the device, noticeably changing her voice. A preferred option would be a clip-on micro, which would ensure better capture, make it feel more natural (instead of "talking into a small box") and ensure a constant level of audio input.
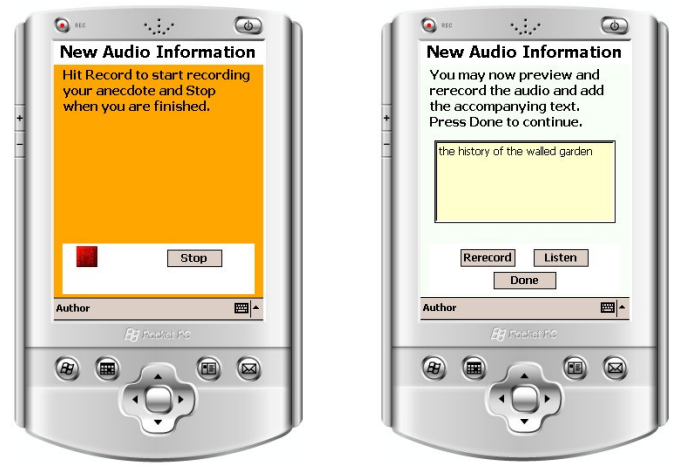

Figure 5: Recording audio.

Sue imagines that one could "almost use it like a little notebook, if you think of something just take it out. Building it up gradually (the content for the system)." After returning to the house she comments that it "would be wonderful to have it with you when you're outside, when you see some- thing, add that on top of the basic tour" and can imagine this to become part of the staff's daily routine. This fits in with previous comments by curators that they would like to continuously change content like they tend to change tours now, and that authoring should be a natural part of everyday activities that does not take extra effort. Yet for getting used to recording and starting the content base, Sue would prefer to do a full garden tour, to "get into a natural flow, rather than walking up to a location and starting there," and adds "you get the ideas once you actually start using it."

Sue quickly understood how to create new locations and to name them using the two options provided for the trial. The first allows the author to create a new location based around the current position. The author enters a name for the location and the last recorded GPS position is used to generate a circular region. The second method of authoring, based on the manual process performed by the researchers at the outset of the project, is to walk out a GPS region. As can be seen in Figure 6 the author first starts within the region they wish to specify and enters a name for it. They then walk slowly around the perimeter of the region, pressing 'Done' to complete the process. The GPS log is automatically processed to create a new location with a region defined by the convex hull of the area walked out. A convex hull was chosen for simplicity in this case however more complex area generation algorithms could be imagined.
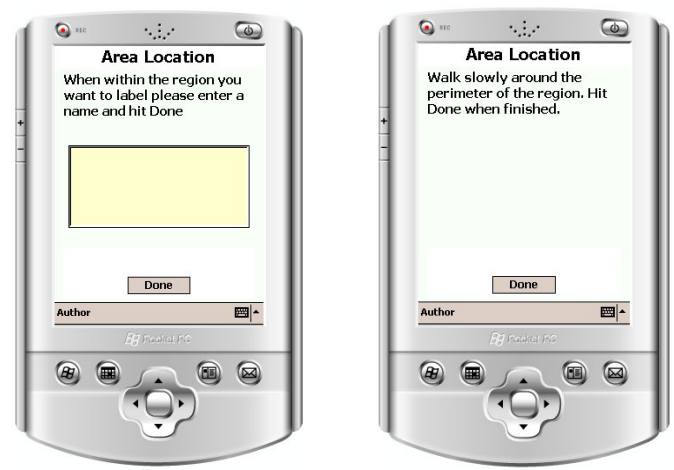

Figure 6: Defining location by walking a perimeter.

Although Sue used the two provided options with no difficulty, when looking to create anecdotes for the wilderness (a sprawling area of woodland), neither of the two methods seemed appropriate or intuitive to her for such a large area. Instead she wished to "start a commentary here and finish it, then start a commentary at the other end and finish it" in order to define this region. Here, the desire is to create locations as a side-effect of the act of recording audio rather than as an explicit a-priori act. As the GPS logs are recorded during the authoring process this could be implemented as an additional interface to the creation of locations.

Sue also is aware that mobile authoring will be only part of the work and that one will work in different ways with the content additionally. While walking around the grounds with us she comments "Presumably the next stage after this is you're going to go back and play with the clips and see how they fit in (...) " This is exactly what our desktop authoring environment, which she had not seen at this point, is intended for. Sue's comment indicates how the curators work practices might readily adapt to using the system. Being 
shown the desktop system later in the house, she can imagine doing this kind of work especially over the winter, and does not feel it is too much work. Sue after the first short explanation on the system explains "you can build tours, that's brilliant (...) you have all your clips there, here you can shuffle them about and put them any way you want."

She can imagine using this facility to create a new tour by selecting a set of clips for a specific visitor group "take the relevant bits and load it on and put it on the machine. If anybody else could do it and put a tour together that would be good." If another visitor group interested in similar issues comes one could reuse the tour or add to it. Thus instead of categorizing single clips, we might have a kind of bottom-up ontology evolving over time, through clips being selected for specific tours. Sue furthermore emphasizes that every tour needs an introduction, middle and conclusion, and that she would like the device to always start with a specifically created but very basic introductory sequence "to put everything in context," no matter in which location visitors start out from.

One problem encountered during the authoring walk outside and discussed in the subsequent interview was a need to sometimes create content outside of a location and then attach it to the location later. In this case there was a desire not to walk over the emerging snowdrops in the wilderness yet still wanting to record information about the wilderness. At other points unwanted background noise (busy gardeners) made recording in some locations awkward. In such situations it would be useful to record content outside of the intended location and later-on move it (e.g. on a map interface or by attaching different location metadata) to its goal location.

Typing with the keyboard was a bit cumbersome, and Sue used only short keywords. She later suggested that after defining a location (in-situ), clips recorded in this location should be numbered automatically using the location name as prefix. When revisiting the data, one might change clips' names. Overall the mobile device with its tiny keyboard does not lend itself to text input. Being asked for further things she would like to record, Sue mentions notes to herself, e.g. reminding her that some areas of the garden might be muddy at certain times of the year or less suited for elderly visitors.

As typing text is cumbersome, we can imagine adding other categories of audio recording to the menu which on the (non in-situ) overview are depicted differently. Such recordings could then quickly be changed to textual data when revising content. This facility could also be used by teachers to author instructions for fieldtrips, allowing them to either type a few keywords or record a dedicated type of audio comment for later extension into a longer text instruction. Thus there could be 'notes to oneself', 'notes to the system' (e.g. having the system not let people enter the wilderness while snowdrops grow), and 'audio notes for future text instructions'.

Finally, Sue observed that she would not want to use the device during tours that she is giving in person, as she felt it would be distracting. Instead she could imagine handing out the device to visitors after a basic garden tour so they can continue to explore the grounds on their own and focus on aspects of the grounds and landscape that were of most interest to them. Visitors might also be able to record their questions using the device, providing feedback and ideas to curators, driving the creation of new content to keep the system evolving.

\section{Summary of results}

we believe that most of these apply to other, comparable settings

- Use of the device incurs a change of process for users, e.g. a need to think of what to say first before recording, consciously devising stories, but this is felt to be learnable as it builds upon and extends current practice.

- There may be a need for an explicit effort at the outset to fill the system with basic content.

- There should be different ways to define locations both a-priori and post-hoc.

- There should be an option to 'relocate' content after creating it.

- Text input in-situ is difficult and cumbersome on a PDA, yet users need a small and light device. Given our two-phase authoring process, the use of preliminary audio notes that can be expanded and typed later would be useful.

- Using the same device for authoring and experiencing tours enables us to utilize the device as feedback mechanism for curators.

- The trial confirmed the viability of the notion of incremental building up and changing of content as an integral part of the curators work practice.

\section{CONCLUSIONS}

Through a series of focused co-design workshops aimed at developing a location aware pervasive literacy experience for schoolchildren we have begun to draw up requirements for the in-situ authoring of such experiences by domain experts rather than researchers. Curators and teachers both found it easy to design the experience and create the content when placed in the environment in which they will take place, but also found subsequent, more reflective authoring activities on a meta-level, selecting and sorting content, useful.

This led to the development of a prototype in-situ authoring system which allowed the curators to construct new information and define names for locations in the grounds of the house. These trials have given us a better understanding of how the curators view such tools and how they can be incorporated into their normal activities to allow for the continual evolving of a corpus of information that can be repurposed for a variety of pervasive experiences.

An in-situ approach to authoring content is not without its problems, such as the occasional need to capture and re-express views. In giving tours the curators might stop at a certain location and describe for the visitors the view of the church, or the view up the avenue of trees. This focus of commentary is not captured by a simple location system and differs from the requirements that might exist in a more traditional museum space where a location could be tied very closely to an exhibit. The current incorporation of a $3 \mathrm{D}$ compass into the system is allowing us to capture 
the direction in which the device is pointing and through that, the possible focus of the curator.

Further trials are being used to explore the validity of this approach and experiment with how this may be incorporated into the visitors interface. During a recent workshop with teachers we discussed how to redesign their experience and went around Chawton House grounds with the PDA, making notes, creating content etc, while in-situ. Then, they used a desktop editor to change the previous cards, add their new ones, and play around with the groupings. Experiences in this informal trial have been very positive and the design for the next fieldtrip will be continued using the new system.

\section{ACKNOWLEDGMENTS}

This research is funded by EPSRC IRC project "EQUATOR" GR/N15986/01. Eva Hornecker and John Halloran were based at the University of Sussex for the period of the research reported on. The authors wish to acknowledge their partners on the Chawton House project: Chawton House Library, Whiteley Primary School, and the University of Bristol.

\section{REFERENCES}

[1] G. D. Abowd, C. G. Atkeson, J. Hong, S. Long, R. Kooper, and M. Pinkerton. Cyberguide: a mobile context-aware tour guide. Wireless Networks, 3(5):421-433, Oct. 1997.

[2] R. Ballagas, M. Ringel, M. Stone, and J. Borchers. istuff: a physical user interface toolkit for ubiquitous computing environments. In Proc. of CHI '03, pages 537-544. ACM Press, New York, NY. 2003.

[3] K. Cheverst, N. Davies, K. Mitchell, and A. Friday. Experiences of developing and deploying a context-aware tourist guide: the guide project. In Proc. of the Sixth Annual International Conference on Mobile Computing and Networking, Boston, Massachusetts, USA, pages 20-31. ACM Press, 2000.

[4] W. Grant. Wireless coyote: A computer-supported field trip. Communications of the ACM, 36(2):57-59, Feb. 1993.

[5] J. Halloran, E. Hornecker, G. Fitzpatrick, M. J. Weal, D. E. Millard, D. T. Michaelides, D. G. Cruickshank and D. C. De Roure Unfolding Understandings: Co-designing UbiComp In Situ, Over Time. In Proc. of DIS 2006, ACM (2006), in press.

[6] J. Halloran, E. Hornecker, G. Fitzpatrick, M. J. Weal, D. E. Millard, D. T. Michaelides, D. G. Cruickshank and D. C. De Roure Using UbiComp to support childrens creative writing. In Proc. of IDC 2006, ACM (2006), in press.
[7] G. Iacucci, J. Kela, and P. Pehkonen. Computational Support to record and re-experience visits. Personal and Ubiquitous Computing 2004(8): 100-109

[8] G. Lane. Urban tapestries: Wireless networking, public authoring and social knowledge. Personal and Ubiquitous Computing, 7(3-4):169-175, July 2003.

[9] Y. Li, J. I. Hong, and J. A. Landay. Topiary: a tool for prototyping location-enhanced applications. In Proc. of the ACM Symposium on User interface Software and Technology (UIST'04), pages 217-226. ACM Press, New York, NY, 2004.

[10] E. Mendelowitz and J. Burke. Kolo and nebesko: A distributed media control framework for the arts. In Proc. of Distributed Frameworks for Multimedia Applications (DFMA 05), pages 113-120, 2005.

[11] M. W. Newman, J. Z. Sedivy, C. M. Neuwirth, W. K. Edwards, J. I. Hong, S. Izadi, K. Marcelo, T. F. Smith, J. Sedivy, and M. Newman. Designing for serendipity: supporting end-user configuration of ubiquitous computing environments. In Proc. of the Conference on Designing interactive Systems (DIS '02), pages 147-156. ACM Press, New York, NY, 2002.

[12] P. Pan, C. Kastner, D. Crow, and G. Davenport. M-Studio: an authoring application for context-aware multimedia. In Proc. of the Tenth ACM international Conference on Multimedia (MULTIMEDIA '02), pages 351-354. ACM Press, New York, 2002.

[13] Y. Rogers, S. Price, D. S. Fraser, C. Randell, M. J. Weal, and G. Fitzpatrick. Ubi-learning Integrates indoor and outdoor experiences. Communications of the ACM, 48(1):55-59, Jan. 2005.

[14] D. Salber, A. Dey, and G. Abowd. The context toolkit: Aiding the development of context-enabled applications. In Proc. of CHI'99, pages 434-441, 1999.

[15] M. J. Weal, D. G. Cruickshank, D. T. Michaelides, D. E. Millard, D. C. De Roure, E. Hornecker, J. Halloran, and G. Fitzpatrick. A persistent infrastructure for augmented field trips. In Proc. of ED-MEDIA 06 (to appear), 2006.

[16] M. J. Weal, D. G. Cruickshank, D. T. Michaelides, D. E. Millard, D. C. De Roure, E. Hornecker, J. Halloran, and G. Fitzpatrick. A reusable, extensible infrastructure for augmented field trips. In Proc. of PerEL 2006, 2nd International workshop on Pervasive eLearning, Pisa, Italy. pages 201-205, 2006. 